\title{
Soil and water conservation in terraced and non-terraced cultivations - a massive comparison of 50 vineyards
}

\author{
Anton Pijl ${ }^{1}$, Wendi Wang ${ }^{1}$, Eugenio Straffelini ${ }^{1}$, and Paolo Tarolli ${ }^{2}$ \\ ${ }^{1}$ University of Padua \\ ${ }^{2}$ University of Padova
}

July 23, 2021

\begin{abstract}
Understanding the soil and water conservation (SWC) impact of steep-slope agricultural practices (e.g. terraces) has arguably never been more relevant than today, in the face of widespread intensifying rainfall conditions. In northern Italy, a diverse mosaic of terraced and non-terraced cultivation systems have historically developed from local traditions and more recently from the introduction of machinery. Previous studies suggested that each vineyard configuration is characterised by a specific set of soil degradation patterns. However, an extensive analysis of SWC impacts by different vineyard configurations is missing, while this is crucial for providing robust guidelines for future-proof viticulture. Here, we provide a unique extensive comparison of SWC in 50 vineyards, consisting of 10 sites of 5 distinct practices: slope-wise cultivation (SC), contour cultivation (CC), contour terracing (CT), broad-base terracing (BT) and diagonal terracing (DT). A big-data analysis of physical erosion modelling based on high-resolution LiDAR data is performed, while four predefined SWC indicators are systematically analysed and statistically quantified. Regular contour terracing (CT) ranked best across all indicators, reflecting a good combination of flow interception and homogeneous distribution of runoff and sediment under intense rainfall conditions. The least SWC-effective practices (SC, $\mathrm{CC}$, and DT) were related to vineyards optimised for trafficability by access roads or uninterrupted inter-row paths, which create high upstream-downstream connectivity and are thus prone to flow accumulation. The novel large-scale approach of this study offers a robust comparison of SWC impacts under intense rainstorms, which is becoming increasingly relevant for sustainable future management of such landscapes.
\end{abstract}

\section{Hosted file}

Manuscript1.1_c.docx available at https://authorea.com/users/427171/articles/531403-soiland-water-conservation-in-terraced-and-non-terraced-cultivations-a-massive-comparisonof-50-vineyards

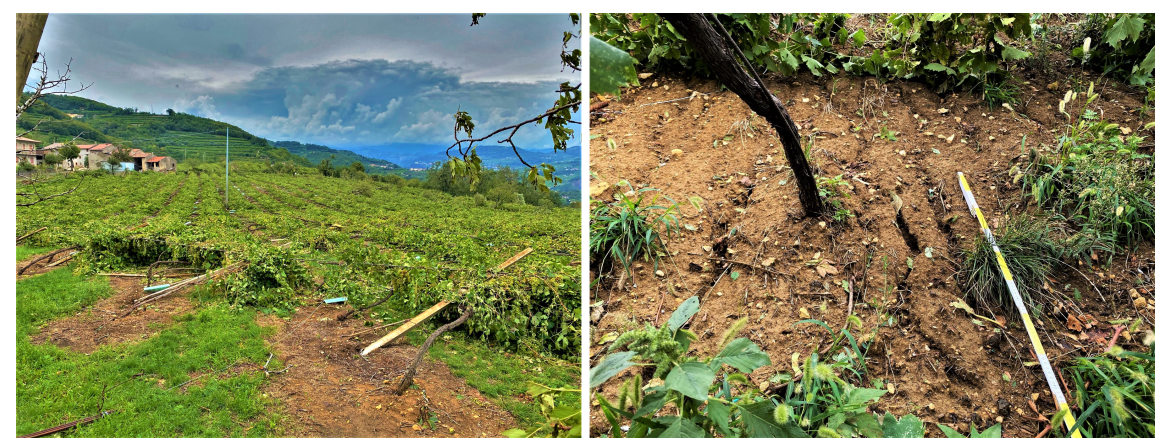



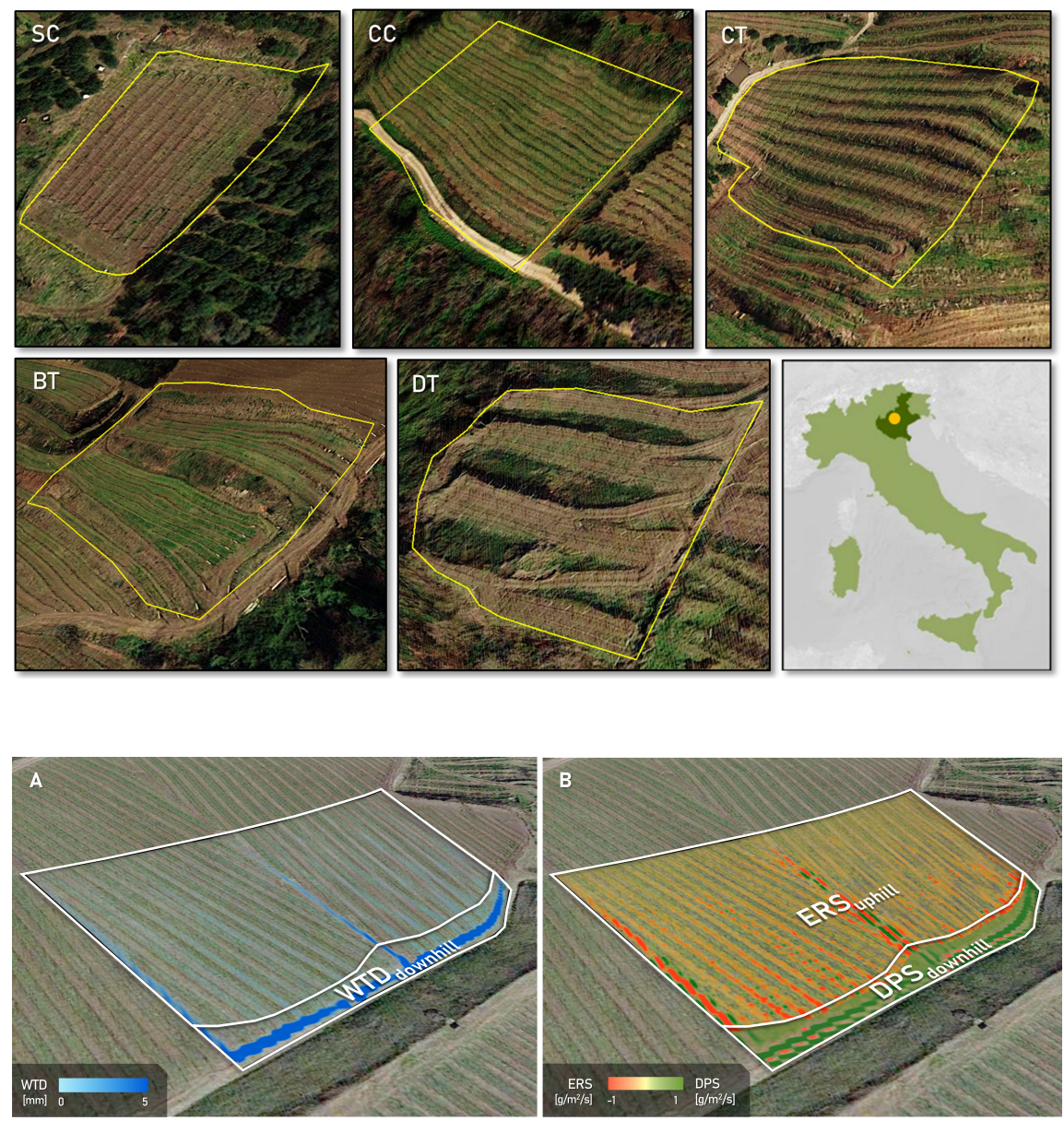

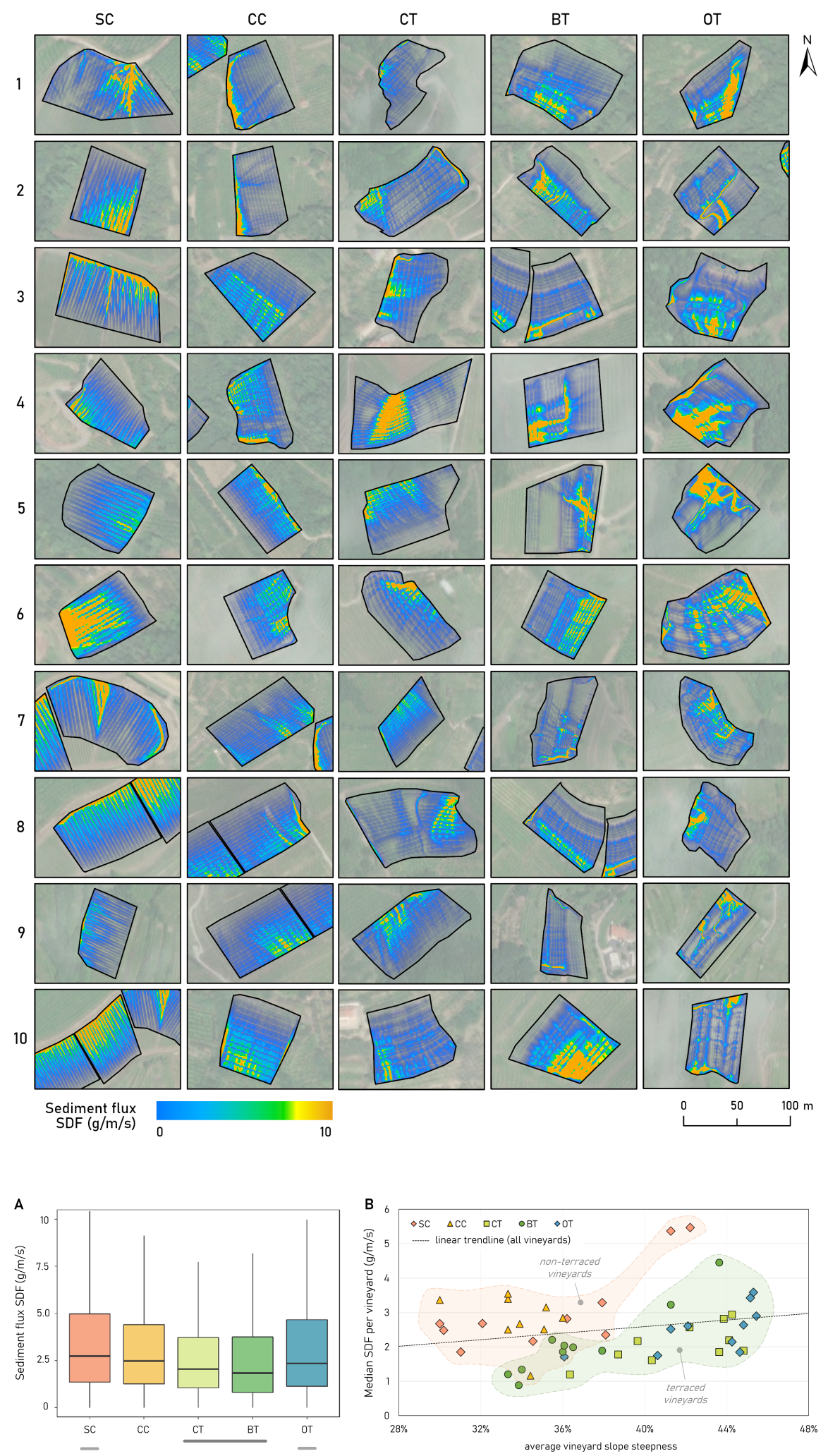

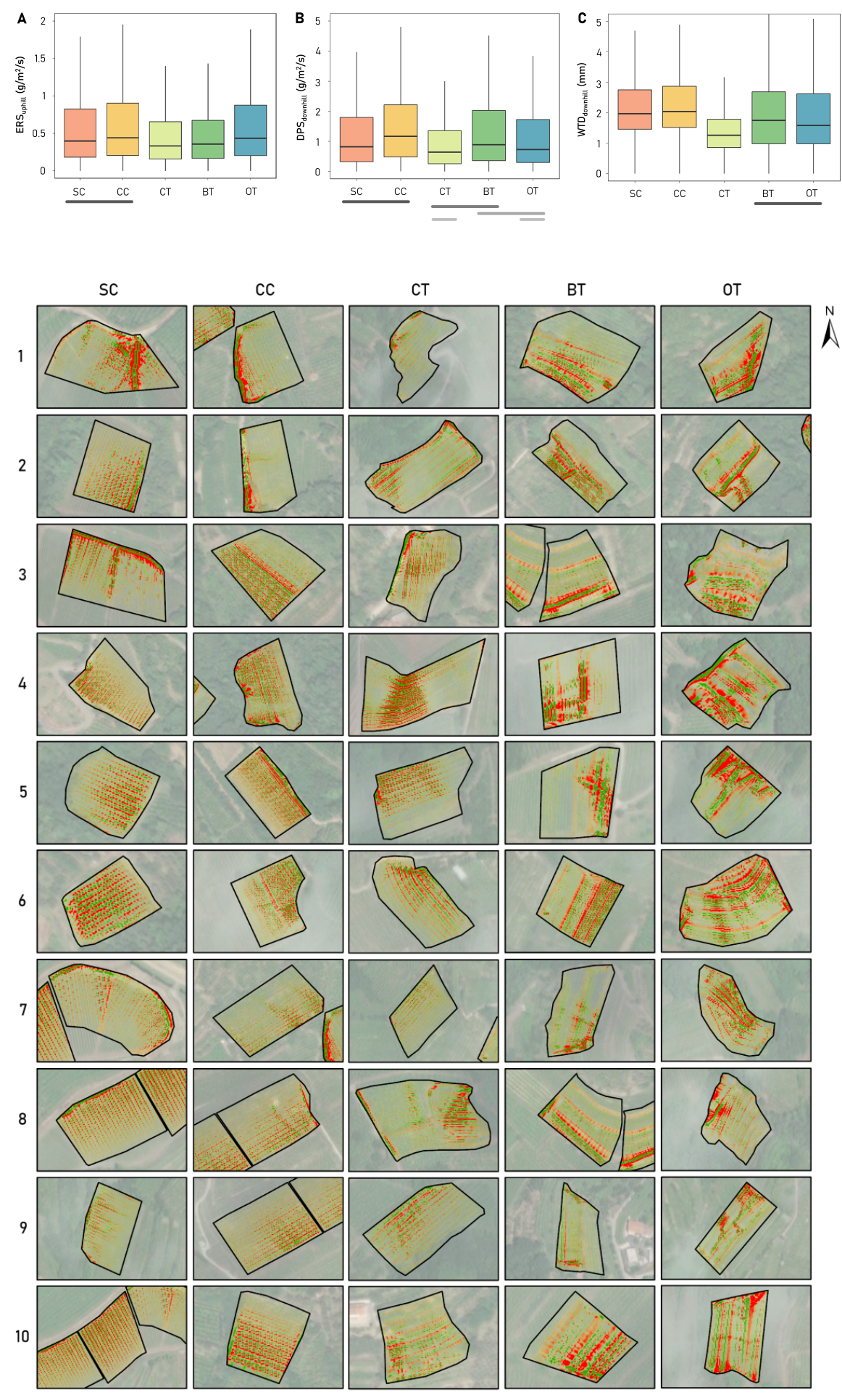

Erosion ERS

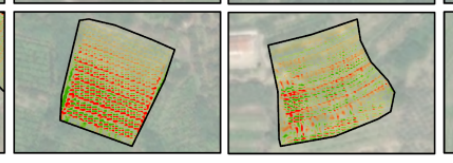

Deposition DPS

$\left(\mathrm{g} / \mathrm{m}^{2} / \mathrm{s}\right)$

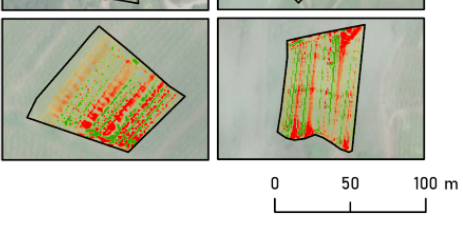




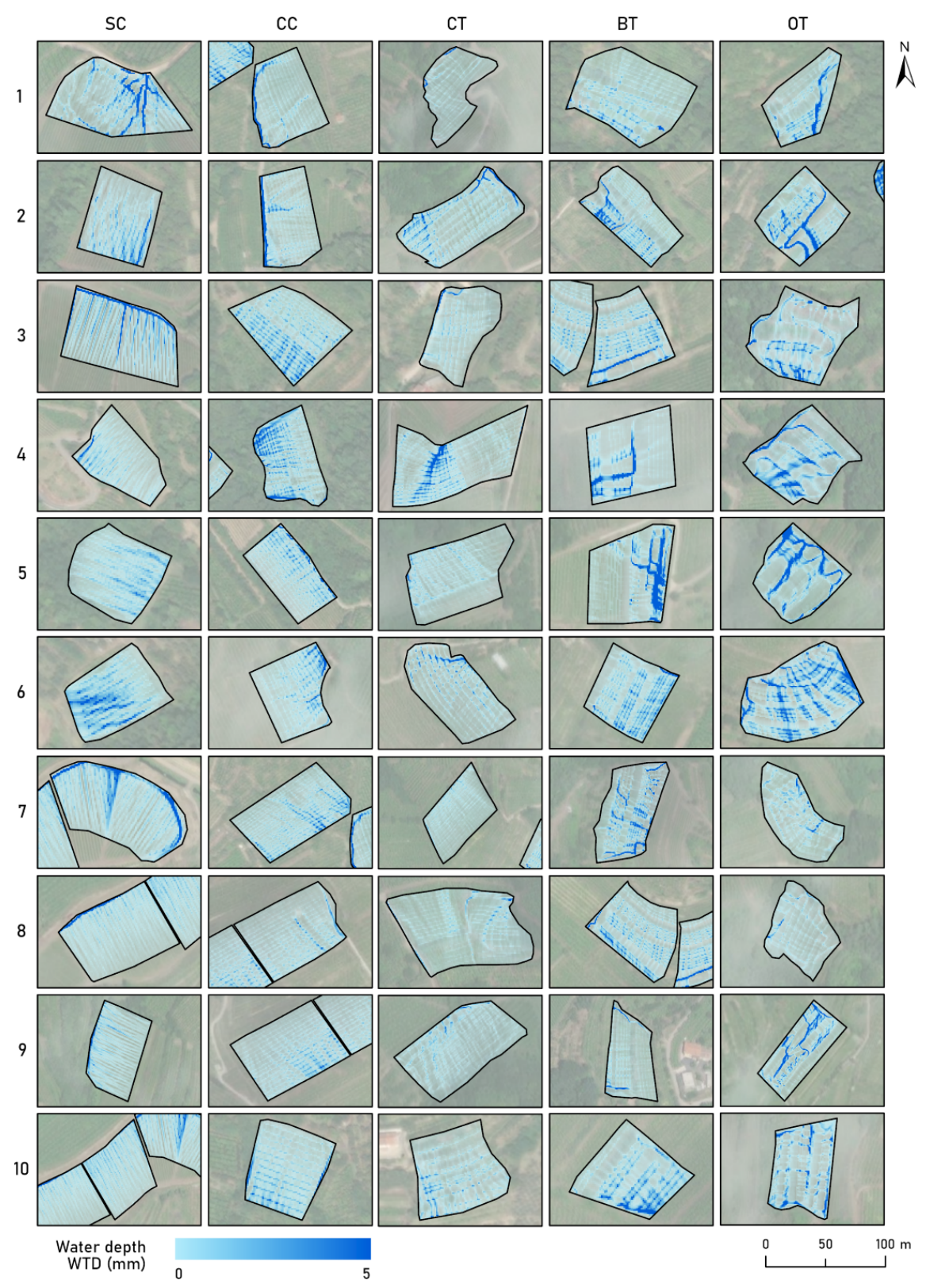

